\title{
The Fourth Party Logistics Development Research in Electronic Commerce
}

\author{
Sun Huimin \\ Engineering Training Center \\ Shenyang Aerospace University \\ Shenyang, China \\ Sunhuimin@sau.edu.cn
}

\begin{abstract}
With the fast development of social economy as well as e-business and information technology, demands for logistics system are becoming higher and higher, which results in constant revolution of logistics mode and constant transformation from traditional logistics to modern logistics. In order to solve problems existing in logistics service of ebusiness, we are here to introduce fourth-party logistics. By integrated operational mode of fourth-party logistics, we can better satisfy the trade need of e-business and develop our ecommerce business more stably.
\end{abstract}

Keywords-fourth-party logistics, e-business, logistics operation, network information technology

\section{INTRODUCTION}

In recent years, with the fast development of ecommerce information technology, enterprises have to develop e-business as their main business since various business activities are connected to internet. However, although online transaction among enterprises is very easy due to development of network information technology and electric information technology, offline trading has become difficult because transportation costs several days or longer while information transmission needs only a few minutes, which will surely lengthen the time of transaction to great extent.

Therefore, the fourth-party logistics emerged at the right moment for solving logistics problems in e-business. The fourth-party logistics is an integrated logistics, which can design the most rational supply chain to solve ebusiness's need for logistics supply chain by making full use of electric information technology, information resources, various talents and so on so that the logistics operation can be more effective and the production and logistics can be more transparent. By fourth-party logistics, united supply chain can be established among supplier, sales agent and customers to form a relatively stable cooperation for shared interest. Through the features of fourth-party logistics and e-business, we can see fourthparty logistics is right the countermeasure to the development of e-business, and in return, the integration ability of e-business network information can provide platform for the development of fourth-party logistics. Therefore, fourth-party logistics has very good prospect under the vigorous e-business. Only if we establish national highway port for logistics and integrate resources from various logistics enterprises with intranet, logistics in our country can possess strong competitiveness internationally

\section{FOURTH-PARTY LOGISTICS- - THE NEW IMPETUS FOR THE DEVELOPMENT OF E-BUSINESS}

Since the long-term backward development of thirdparty logistics can't meet the need of e-business's development, professionals thus proposed the suggestion of fourth-party logistics service supplier by learning from overseas. Seeing from the theory itself and actual situation overseas, there is not any other means better than the fourth-party logistics service supplier in solving the existing problems in our country.

\section{A. Playing a key role in solving the "bottleneck" of logistics}

Under the e-business era, information technology has been highly developed, while the overall level of logistics in our country is too low to satisfy people's need with slow development. Besides, the modern third-party logistics under new economy has not been mature enough to satisfy customers' needs, let alone drive the development of ebusiness. That's why we are in urgent need of fourth-party logistics.

The integration ability of resources and management ability of supply chain by fourth-party logistics are all new impetus to the development of logistics. Besides, ebusiness can be further developed due to information sharing and allocation by fourth-party logistics.

\section{B. The overall operational cost can be reduced by fourth-party logistics}

In China, development of third-party logistics is still unsound and imperfect because most of them can only meet the delivery and storage. If an enterprise wants to outsource their logistics business to third-party logistics, it needs to invest lots of money, while third-party logistics enterprise itself also needs to invest much cost to realize the whole optimization while meeting the needs from partners.

While the operational mode of fourth-party logistics can solve this problem well by integrating superior resources among cooperative partners. Meanwhile the efficiency of logistics business can be raised with low cost and mutual benefits.

\section{C. fourth-party logistics is the basis of successful supply chain operation}

The operation of supply chain is combination of logistics, information flow and capital flow. For most 
supply chains, the final purpose of information sharing and capital allocation is to realize the delivery of goods and increase of value, during which logistics is the core and basis of supply chain operation.

By designing and recreating professional supply chain scheme for customer enterprises, fourth-party logistics can supervise logistics and make the process of supply chain more professional and efficient with timely information processing, which can lower the logistics cost constantly and achieve logistics service of high quality.

\section{The fourth-party logistics standardize and normalize the logistics service}

Service supplier of fourth-party logistics possesses highly integrated information platform, which can supervise the whole logistics operation accurately including timely feedback of emergence and constant supervision and improvement of service quality so that the logistics quality can be better improved and logistics service can be constantly standardized and normalized.

Close cooperation by various sections can make good use of resources so as to raise the efficiency and lower the cost. Therefore, the standardization and normalization of logistics service is significant for the development of logistics.

\section{SUGGESTIONS AND COUNTERMEASURES TO THE OPERATION OF FOURTH-PARTY LOGISTICS}

\section{A. Strengthen the planning and construction of logistics infrastructures}

Our country should attach great importance to logistics since it will affect the development of e-business economic mode directly. So investment and construction on the logistics infrastructures should be strengthened to lay strong foundation for logistics operation. Meanwhile, collective logistics base or delivery center should be established in rational locations so as to speed up the standardization and normalization of logistics development

\section{B. Vigorously develop the third-party logistics}

As we all know, third-party logistics is important to fourth-party logistics. As an integrator, mature resources of third-party logistics are necessary to fourth-party logistics because efficient logistics resource is one of its core competitive abilities. To appeal to the development of fourth-party logistics service supplier and develop modern logistics, it is important to support small and medium-sized logistics enterprises while cultivating third-party logistics enterprise of large scale. Among the three flows of ebusiness economic mode, logistics is the most special one. It is the most difficult section with the longest time, and it is executed by third-party logistics.

\section{Speed up the information construction of logistics}

Under the e-commerce environment, information is the most competitive factor, so it is of top priority to speed up the information construction of logistics. The purpose of fourth-party logistics is to solve the problems of logistics resources allocation under e-commerce mode while accelerating logistics information construction is a necessary process. By employing internet technology and information system, we can take modern logistics online by making full use of various logistics sections. Thus logistics in our country can be elevated to an international high.

\section{Accelerating the cultivation of logistics talents}

Talents are invaluable property of an enterprise and they are absolute competitive power of an enterprise. As for advanced four-party logistics enterprise, they need large quantities of comprehensive logistics talents particularly. At present, we are not good at cultivating talents for fourth-party logistics. Therefore, we need to build a talent team with modern professional knowledge by practical cultivation. By correct management and decision, correct development direction of fourth-party logistics can be guaranteed.

\section{ANALYSIS ON THE DEVELOPMENT TREND OF FOURTH-PARTY LOGISTICS IN E-BUSINESS}

\section{A. Transformation of fourth-party logistics operation}

1) Realizing the cooperative development between third-party logistics and fourth-party logistics

The development of fourth-party logistics is based on mature third-party logistics market, but the development of third-party logistics in our country is still unsound with less third-party logistics enterprises of large scale. Therefore, we are now needing a bidirectional development of fourth-party logistics with more attention on third-party logistics. That is to say, third-party logistics and fourth-party logistics should be developed with mutual support, and then more attention can be put on fourth-party logistics for a highly integrated logistics.

During the further development of logistics globalization, more and more international logistics companies have entered into Chinese market, which put new challenges to our domestic logistics companies; meanwhile deficiencies of third-party logistics enterprises become more obvious.

At the same time, it's a good chance for the development of third-party logistics since we can find countermeasures to the existing problems by formulating perfect development plan so as to lay basis for the development of fourth-party logistics.

2) fourth-party logistics Enterprises of e-commerce websites are transformed to fourth-party logistics

In the past, third-party logistics was transformed to fourth-party logistics, but in my opinion, we should own self-logistics enterprises if we want to change e-business enterprise into fourth-party logistics faster than third-party logistics enterprise. The mature information platform owned by e-commerce website enterprise provides information technology basis for logistics platform; besides they just need to find logistics cooperative partner without worrying about the orders after the transformation, which can save lots of cost with faster steps.

At present, e-commerce is eager for logistics earnestly. Therefore, it'll be appropriate if the e-business enterprise can operate logistics by itself since the enterprise itself knows better about the disadvantages of its logistics and it can make up for it independently.

\section{3) Cultivation and Introduction of Talents}

The fourth-party logistics service provider has quite a large demand for talents, including talents of logistics, ebusiness, information technology, market and so on. 
Therefore talents adaptable to the development of enterprise should be constantly cultivated while attracting high-end talents.

Cultivation is a long process, during which we can mine high-end talents from other enterprises to support our normal operation, and then professionals can be invited to cultivate employees. In the later period, we can cultivate talents independently by ourselves with mature and stable talents.

\section{B. Develop the Information Standardization Construction}

The abnormal information construction has restrained the service quality of fourth-party logistics to great extent. Therefore information standardization will be the development trend of global fourth-party logistics enterprises.

1) Accelerating the Information Standardization Construction of Logistics by Linking to International Level

The fourth-party logistics in developed countries has a longer development history than that of our country with more mature and advanced information technology, so there's must be something to be learned in terms of information standardization.

Thus we can study their advanced management way and logistics technology by linking to the world so that our logistics can study and grow in the competition. The development of fourth-party logistics in our country is still in the early stage, logistics infrastructure and knowledge mastery are decisively important to the development of fourth-party logistics service provider. So the best way is to imitate before innovating.

2) Competition to cooperation - - by integrating resources

Although logistics in our country is under the stage of stable development, third-party logistics enterprises, information technology enterprises as well as management consulting enterprises are still immature with lower strength compared to other countries. Therefore, it is of great benefits to transform competition to cooperation for the construction of information standardization by using resources in the whole industry.

Common information system or standard information construction can be established among cooperative enterprises for a better communication and utility of resources. Abnormal information construction can be relieved in the whole logistics industry by this way but it makes information transparent. Therefore information standardization construction needs certain trust among enterprises besides technology.

3) Accelerating the integration between e-business and modern logistics industry

Development of e-commerce enterprises in our country has begun to take shape with breakthrough in technology. With the favorable conditions of technology, talents and funds, we can accelerate the fusion of e-commerce and modern logistics industry by integrating various factors so as to establish national public information platform for logistics to make up for the gap in information technology. We can manage and integrate information by advanced fourth-party logistics management idea for a convenient supervision of national logistics service so as to improve efficiency and to compete with international logistics with our own creative way.

\section{Optimization of fourth-party logistics service}

\section{1) Link to e-commerce platform}

What the fourth-party logistics pursues is an integrated and united operation means with enough corporations. Therefore, if e-commerce platform is linked to fourth-party logistics, then customers can choose logistics companies that they trust independently. The only thing that fourthparty logistics platform needs to do is to type in the introduction of cooperative company.

2) Providing information for cooperative partners actively

The fourth-party logistics service platform can make quick integration and processing of information without being limited to customers' active inquiry. The fourthparty should master the industry trend by matching the latest information with resources in cooperative enterprises so that information can be sent to enterprise who needs it most for a constant sustainable development.

3) Establish Evaluation System for Credits and Service of Cooperative Partners

Since the fourth-party logistics has a lot of cooperative partners, so it'll be troublesome to track service survey by itself. Therefore, fourth-party logistics enterprise can better receive information about their service and credit from customers' direct feedback of service quality as well as suggestions. By classifying the service and credit, customers can choose a long cooperative partner by themselves.

4) Intelligentize management and service ofsupply chain

The supply chain is important since the core industry of fourth-party logistics is revolution, recreation and management of logistics supply chain. Intelligent management and service of supply chain should be supported by advanced network information technology. With the information safety as precondition, it realizes the seamless connection inside the whole supply chain by using wired or wireless communication network technology of long or short distance. By choosing different network in different sections, supervisors can manage and integrate sections effectively and specifically. While disclosing service conditions in some sections that customers care, information in other sections can be effectively protected.

\section{CONCLUSION}

Nowadays, logistics decides the currency circulation in economic activities, and the backward development may restrain the development of e-business. The proposal of fourth-party logistics can solve problems in developing ebusiness effectively. However, development of fourthparty logistics service supplier also has some difficult problems. For these problems, operation mode of fourthparty logistics service provider can fully relieve the pressure of logistics development in our country, and meanwhile it can further promote the development of third-party logistics enterprises as well as e-business.

After the analysis and comprehensive consideration of national conditions and situations, development trend of fourth-party logistics service provider in our country is 
described. It is a shortcut to learn advanced logistics culture from other countries, but we'll be also faced with risks. Our domestic logistics will be surely impacted by overseas mature logistics, but it is a good choice if we want to lay sound basis for our fourth-party logistics quickly. We can first imitate others, and then we can finally create fourth-party logistics service provider of Chinese-style.

\section{REFERENCES}

[1] Zhiqing Zhao,Xianjun Pang, The development of Chinese fourth party logistics based e-commerce, ICEE 2011, 2011.

[2] Lan Jianyi, Li Hui, Reliability Analysis of Logistics Distribution in Electronic Commerce, Shanghai University,

[3] Lidan Tian Chunxiao Fan Junwei Zou Xiaoying Zhang, Analysis and Research for Fourth Party Logistics Based on Internet of Things, IMCCC 2011,2011.

[4] Wangfeng, Analysis on the Status quo and Countermeasures of Fourth-party Logistics in Our Country, Science and Education, the 28th issue, 2009.

[5] Yang Dongbao, Zhuo Chenguang, Discussion on Fourth-party Logistics under E-business Environment. Theoretical Science.

[6] Zhang Haitao, Application of Fourth-party Logistics in Ebusiness in Our Country, School of Economics and Management in Beijing Jiaotong University, Beijing.

[7] Zhao Hanqing, Zhangqing, Biran, Analysis of Fourth-party Logistics Based on E-business Service in China, Logistics Science, the 10th issue, 2013.

[8] Xuping, Problems As Well As Countermeasures to E-business Logistics in China, Hei Longjiang Science and Information, the 11th issue, 2011.

[9] Wang Xuezhi, Wu Yayu, Chen Shengyi, Lan Shicai, Study on the Development Trend of Fourth-party Logistics under the Background of E-business, Logistics Science, the 4th issue, 2012.

[10] Liu Bosong, Study on the Wise Construction of Supply Chain Served for Fourth-party Logistics Enterprises , Ningbo University, Jan, 2011
[11] Zhang Yunyun, Leiwei, Zhuxin, Pu Yingling. Features and Strategies of Modern Logistics Under the Environment of Ebusiness, Chinese E-commerce, the 22nd issue, 2013.

[12] Yin Yanhai, Exploration of the Prospect of Fourth-party Logistics in Our Country, Chinese Market, the 10th issue, 2010.

[13] Zhouwei, Study on the Profit Model of Fourth-party Logistics Enterprises in Our Country, 2011.

[14] Liao Chuanmin, Study on the Development of Fourth-party Logistics Under the E-business Environment, Logistics Platform, the 11th issue, 2008.

[15] Zhang Yuntong, Zhang Tiancong, Study on the Development of Fourth-party Logistics in C2C E-commerce, Chinese Business, 2010.

[16] Tang Xinming, Liu Lianhao, Study on the Main Modules and Functions of Fourth-party Logistics Information System, Journals of Hunan Business College, 2009.

[17] Wang Huimei, Wenquan, Study on the Problems of Fourth-party Logistics in Our Country , Enterprise Technological Development, the 7th issue, 2011.

[18] Ma Xinying, Developing Modern Logistics With Advanced Mode, Luqiao Comment, 2013.

[19] Lu Weicai, Study on the Core Competitiveness of Fourth-party Logistics Enterprise, Dalian Maritime University, 2008.

[20] Zhang Yuntong, Study on the Feasibility of Fourth-party Logistics in C2C E-commerce, 2012.

[21] Yang Shasha, Liping, Analysis on the Coordinated Development between Fourth-party Logistics and Third-party Logistics

[22] Leining, Analysis on the Difficulties of Logistics E-commerce Under the Background of Informatization Era, Electric Test, the 8th issue, 2013.

[23] Zhiqing Zhao,Xianjun Pang, The development of Chinese fourth party logistics based e-commerce, ICEE 2011, 2011.

[24] Lan Jianyi, Li Hui, Reliability Analysis of Logistics Distribution in Electronic Commerce, Shanghai University,

[25] Lidan Tian Chunxiao Fan Junwei Zou Xiaoying Zhang, Analysis and Research for Fourth Party Logistics Based on Internet of Things, IMCCC 2011,2011. 